\title{
Use of combined oral contraceptives and risk of venous thromboembolism: nested case-control studies using the QResearch and CPRD databases
}

\author{
Yana Vinogradova, Carol Coupland, Julia Hippisley-Cox
}

Division of Primary Care, University Park, Nottingham, NG2 7RD UK

Correspondence to:

Y Vinogradova

yana.vinogradova@nottingham. ac.uk

Additional material is published online only. To view please visit the journal online (http://dx.doi. org/10.1136/bmj.h2135)

Cite this as: $B M J$ 2015;350:h2135 doi: 10.1136/bmj.h2135

Accepted: 19 March 2015

\author{
ABSTRACT \\ OBJECTIVE \\ To investigate the association between use of \\ combined oral contraceptives and risk of venous \\ thromboembolism, taking the type of progestogen into \\ account.
}

DESIGN

Two nested case-control studies.

SETTING

General practices in the United Kingdom contributing to the Clinical Practice Research Datalink (CPRD; 618 practices) and QResearch primary care database (722 practices).

\section{PARTICIPANTS}

Women aged $15-49$ years with a first diagnosis of venous thromboembolism in 2001-13, each matched with up to five controls by age, practice, and calendar year.

\section{MAIN OUTCOME MEASURES}

Odds ratios for incident venous thromboembolism and use of combined oral contraceptives in the previous year, adjusted for smoking status, alcohol consumption, ethnic group, body mass index, comorbidities, and other contraceptive drugs. Results were combined across the two datasets.

\section{RESULTS}

5062 cases of venous thromboembolism from CPRD and 5500 from QResearch were analysed. Current exposure to any combined oral contraceptive was associated with an increased risk of venous thromboembolism (adjusted odds ratio 2.97, 95\%

\section{WHAT IS ALREADY KNOWN ON THIS TOPIC}

Oral contraceptive pills are known to be associated with an increased risk of thromboembolism (VTE)

Despite comparing third generation contraceptive pills with first and second generation pills, previous studies have had insufficient power to quantify VTE risk with individual drugs, particularly for new or less commonly used preparations such as drospirenone or norgestimate

\section{WHAT THIS STUDY ADDS}

This study, based on national population and prescribing practices in the UK, has sufficient power to provide reliable comparative findings for different formulations of combined oral contraceptives; its findings are comparable to those based on a Danish national cohort study

Preparations containing gestodene, desogestrel, drospirenone, and cyproterone were associated with significantly higher risks of VTE than preparations containing either levonorgestrel or norgestimate

The number of extra VTE cases per year per 10000 treated women was lowest for levonorgestrel and norgestimate, and highest for desogestrel and cyproterone

confidence interval 2.78 to 3.17) compared with no exposure in the previous year. Corresponding risks associated with current exposure to desogestrel (4.28, 3.66 to 5.01$)$, gestodene $(3.64,3.00$ to 4.43$)$, drospirenone (4.12, 3.43 to 4.96$)$, and cyproterone (4.27, 3.57 to 5.11$)$ were significantly higher than those for second generation contraceptives levonorgestrel $(2.38,2.18$ to 2.59$)$ and norethisterone $(2.56,2.15$ to $3.06)$, and for norgestimate $(2.53,2.17$ to 2.96$)$. The number of extra cases of venous thromboembolism per year per 10000 treated women was lowest for levonorgestrel $(6,95 \%$ confidence interval 5 to 7$)$ and norgestimate $(6,5$ to 8$)$, and highest for desogestrel $(14,11$ to 17$)$ and cyproterone $(14,11$ to 17$)$.

\section{CONCLUSIONS}

In these population based, case-control studies using two large primary care databases, risks of venous thromboembolism associated with combined oral contraceptives were, with the exception of norgestimate, higher for newer drug preparations than for second generation drugs.

\section{Introduction}

About 9\% of women of reproductive age worldwide use oral contraceptives. This percentage rises to $18 \%$ of women in developed countries and $28 \%$ of women in the United Kingdom. ${ }^{1}$ Combined oral contraceptives form a substantial proportion of these, particularly in more developed nations. Although combined oral contraceptives are generally effective in preventing pregnancy, they have measurable side effects such as venous thromboembolism (VTE). VTE is important, not only because of the prolonged time over which women might be exposed to such contraceptives, but also because VTEs are potentially avoidable and can be fatal.

Previous studies have shown varying risks for different types of oral contraceptives (such as third generation pills compared with first or second generation pills), but such studies were done some years ago, ${ }^{2-6}$ and tended not to include new preparations containing drospirenone. Also, previous studies have generally had insufficient power to analyse the risks for more recent formulations ${ }^{7-10}$ such as norgestimate. Few studies-only four of those referenced here ${ }^{911-13}$-have included any detailed analyses of dosage and, of these, only Lidegaard and colleagues ${ }^{12}$ have covered a full range of prescribed drugs. Some studies did not control for all potential confounders (such as body mass index or smoking), ${ }^{12}$ while others analysed only healthy users. $^{41114}$ Different methodological approaches in studies have also made it difficult to compare and 
combine the results. ${ }^{15}$ Therefore, although the increased VTE risk associated with combined oral contraceptive drugs is established, the relative risks associated with different combinations remain inconclusive, especially for newer formulations. ${ }^{16} 17$

The UK has some of the largest sources of routinely collected data in the world, with longitudinal primary care records spanning up to 25 years and linked to secondary care data and mortality records. These databases cover many millions of patients, include data both on exposure and outcomes, and therefore are representative of the setting in which drugs are used. This makes the databases ideally suited to large scale safety studies of commonly used drugs. ${ }^{18}{ }^{19}$ In this study, we have used the two largest of these databases, QResearch (www.qresearch.org) and Clinical Practice Research Datalink (CPRD, www.cprd.com). Both have been used for earlier studies of associations between drug prescribing and VTE risks. ${ }^{4} 510142021$

Our objective was to quantify the associations between use of combined oral contraceptives and risk of VTE, adjusting for comorbidities and other available confounding factors. In particular, we were interested to analyse risks associated with newer or less used preparations such as drospirenone or norgestimate, quantify risks associated with various types of progestogen, and analyse the effect of different doses of oestrogen on VTE risks. To make the study more comparable with previous studies, we also replicated analyses for different subgroups by age and health status and for VTE cases with anticoagulation prescriptions.

\section{Methods}

Study design

The protocol for this study has already been published. ${ }^{15}$ We undertook two similar studies using the CPRD (January 2014 version; 618 UK general practices) and QResearch database (version 38; 722 general practices) to quantify the association between prescribing of combined oral contraceptives and risk of incident VTE. We identified open cohorts of all women who had no records of VTE before the study, were aged 15-49 years, and were registered with the study practices between 2001 and 2013. Within each cohort, we designed two nested case-control studies with incident cases of VTE during the study period. This design was chosen as the most practicable, because it allowed us to work within the maximum extraction capabilities of the databases without losing any of the available cases-and therefore not compromising either the power of the study or the generalisability of the findings. ${ }^{22}$

The methods used in the study followed exactly those of the published protocol, with one difference related to the use of linked data. With respect to case identification, the protocol specified that "the main analysis will be run on all cases with VTE identified from the general practice data.” QResearch is, however, closely linked at the individual patient level to hospital admissions data, and mortality records from the UK Office for National Statistics (ONS, www.ons.gov.uk/; complete for 99.8\% of patients in QResearch, 99.9\% of ONS mortality records, and $98 \%$ of hospital admissions records) ${ }^{23} 24$. So we identified VTE cases if, in QResearch, there was a relevant clinical code in the GP record, linked hospital record, or linked mortality record (web table 1), using the earliest recorded date on any of the three sources as the index date. For CPRD, however, not all practices were linked to these external data, so we could use only general practice records to identify VTE cases in CPRD.

For both databases, we matched each case to up to five controls by year of birth and from the same practice using incidence density sampling. Each control was allocated an index date, which was the date of first VTE diagnosis for the matched case. Eligible women had to have been registered with their practice for at least one year before the index date.

Because records of prescriptions for anticoagulant therapy (BNF 2.8.2) might indicate a previous VTE episode that was not recorded, cases with such records six or more weeks before the index date and controls with such records at any time before the index date were excluded from the analysis. We also excluded women if they had conditions such as oophorectomy, hysterectomy, and sterilisation, which normally preclude use of combined oral contraceptives. Women identified as pregnant or in the first three months after delivery at the index date were excluded, because they were less likely to be users of combined oral contraceptives and have an increased risk of VTE. ${ }^{25}$ Cases or controls with conflicting prescriptions-two or more prescriptions for different combined oral contraceptives issued on the same date for the month before the index date-were also removed from the analysis.

\section{Exposure to oral contraceptive drugs}

Exposure to hormonal contraceptive drugs was based on prescription information in the last year before the index date. The main focus of the study was on individual combined oral contraceptives, which included all the most commonly used preparations in the UK: norethisterone, levonorgestrel, norgestimate, desogestrel, gestodene, and drospirenone (BNF 7.3.1). We included cyproterone, a hormonal treatment for acne, because it is also used as an oral contraceptive owing to its progestogen-like effect on the release of testosterone by the ovaries (BNF 13.6.2). For confounder control, the analysis included oral progestogen only contraceptives (BNF 7.3.2) and non-oral hormonal contraceptives (BNF 7.3.1 and BNF 7.3.2: implants, injections, transdermal patches, intrauterine and vaginal devices).

We investigated the recency of use by calculating the gap in days between the estimated date for the last use of a combined oral contraceptive and the index date, and categorising it as follows: used at index date or last use 1-28 days before the index date (current use); last use 29-365 days before the index date (past use); or no use in the last year before the index date. If a woman was exposed to more than one combined oral contraceptive in the last 28 days, only the latest time used was considered, but an indicator that she had switched type of oral contraceptive in the last 28 days was included in 
the analysis. No use in the last year was a reference category for all analyses unless otherwise stated.

We included the category of past use in the analysis to allow for women having an increased VTE risk associated with previous drug use, either because of a very recent cessation of exposure close to the start of the current use period or because of a delayed start of drug use from a previous prescription, such that some women classified as past users were actually current users. This approach was used only to approximate short term residual and misclassification effects, and should not be interpreted as a measure of long term residual risk. To emphasise this, we have reported odds ratios for past users only in the web tables.

Use of other hormonal contraceptives (oral progestogen only and non-oral hormonal treatments) was similarly categorised into current and past exposure and added to the analysis as confounders. We aggregated the data for combined and progestogen only non-oral contraceptives, because the numbers of current users for combined non-oral contraceptives were low (13 cases and 24 controls in CPRD, 11 cases and 14 controls in QResearch) and lacked power for separate analysis.

Because VTE risk is likely to be highest in the first three months of oral contraceptive use, ${ }^{26}$ we estimated the effect of duration of exposure on current users. We assessed exposure duration by calculating the number of days of exposure within the previous year. If the gap between the end of one prescription and the start of the next was 30 days or less, we considered exposure was continuous and combined the durations of the prescriptions. If a gap was longer than 30 days, only the latest period of exposure was considered.

Length of exposure duration was based on a period of 84 days, the most common length of a contraceptive prescription and also close to the end of the period of highest VTE risk associated with contraceptive use in other studies. ${ }^{7}{ }^{9}$ We classified duration as short term ( $\leq 84$ days) and long term (>84 days), and combined it with recency of use into the following categories: short term current users (new users and restarters), long term current users (prevalent users), past use, and no use in the previous year.

In our samples, three contraceptives-norethisterone, desogestrel and gestodene-were prescribed in combinations having different doses of oestrogen. Owing to evidence of associations between higher VTE risks and higher doses of oestrogen ${ }^{12}$, we undertook a further analysis of current users and categorised separately the oestrogen dose for these preparations (low dose $(20 \mu \mathrm{g})$, normal dose $(30-40 \mu \mathrm{g}))$, based on their most recent prescriptions before the index date. There was only one preparation with a high oestrogen dose (50 $\mu \mathrm{g})$, which was combined with norethisterone. However, since there were only seven current users with this high dose preparation across both databases (one case and one control in CPRD, one case and four controls in QResearch), we included these women in the normal dose category. For all other drugs, only normal dose combinations had been prescribed.

\section{Confounding factors}

We identified the conditions affecting risk of VTE from the UK's health service guidelines related to VTE and hormonal contraceptives (web appendix 2). ${ }^{27}$ Since these conditions might affect the prescribing decisions of doctors, we decided to adjust for these in all analyses. The chronic conditions for any patient had to be recorded before the index date in, to be included. These conditions were cancer, congestive cardiac failure, varicose veins, cardiovascular disease, rheumatoid arthritis, systemic lupus erythematosus, chronic renal disease, asthma, chronic obstructive pulmonary disease, Crohn's disease or ulcerative colitis, and coagulation disturbances (Leiden factor $\mathrm{V}$, protein $\mathrm{C}$ and $\mathrm{S}$ deficiencies).

We also included traumatic events and events leading to immobilisation if recorded in the six months before the index date. These events included acute infections (upper and lower respiratory tract infections, urinary tract infections), surgery or leg/hip fracture, admission to hospital (excluding the previous 30 days before the index date). Non-idiopathic groups were formed from women with any of these chronic conditions or events, and idiopathic groups from women without them.

Obesity and smoking are also mentioned as potential risk factors in the NHS guidelines, so we adjusted all analyses for body mass index as a continuous variable, and for smoking status as the following categories: current smoker (light (1-9 cigarettes/day), medium (10-19), heavy ( $\geq 20$ ); ex-smoker; non-smoker. We used values recorded at the closest date before the index date.

We included polycystic ovary syndrome as a confounder because it is treated with hormonal contraceptives and associated with an increased risk of VTE. ${ }^{28}$ Other conditions treated with hormonal contraceptive prescriptions-acne, hirsutism, and menstrual disorders-were initially considered as potential confounders but their addition to analyses failed to change odds ratios for main exposures by more than $10 \%$, so these were not included in the final study analyses.

Alcohol consumption has previously been considered as a confounder ${ }^{10}$ and, being a potentially important lifestyle factor available from primary care data, ${ }^{29}$ was categorised and included in the analyses (light $(\leq 2$ units/day), medium to heavy ( $\geq 3$ ), ex-use or no use). We also adjusted for ethnic group (white or not recorded, Asian, black, or other), because women in ethnic minorities could have different patterns of contraceptive use $\mathrm{e}^{30}$ and different VTE risks from the white population. ${ }^{31}$

Social deprivation, which can be measured in the UK by the Townsend score, was not included as a confounder in the main analyses because it was not a significant risk factor for VTE in a previous QResearch study. ${ }^{32}$ Furthermore, the CPRD had a large proportion of missing data for the Townsend score, so the inclusion of social deprivation would result in a loss of statistical power in that analysis. However, during the peer review process, we decided to run an additional analysis on QResearch data including the Townsend 
score as a confounder, because the Townsend data were almost complete (available for $99.8 \%$ of cases and controls). We have, therefore, run an additional analysis on QResearch data including the Townsend score as a confounder.

\section{Statistical analysis}

The analyses were run on each database separately. Crude incidence was calculated by dividing the number of cases with incident VTE by the number of person years in the cohorts. Data for oral contraceptive exposure were only available for cases and matched controls rather than whole cohorts, which had higher proportions of older women than the general population. Therefore, we estimated age standardised rates of exposure to any oral contraceptives, using groups of controls before exclusions and directly standardising to the age profile for the UK general population in the relevant year based on data from the UK Office for National Statistics.

We used conditional logistic regression to obtain odds ratios with $95 \%$ confidence intervals. The differences between exposures were assessed using Wald's tests. To account for the log normal distribution for body mass index, we used the logarithm of body mass index for all analyses. Missing values for body mass index, smoking status, and alcohol consumption were imputed using chained equations. ${ }^{33}$ Ten imputed sets were generated, and the imputation model included age, outcome (case or control), index year, all confounding factors (including acne, hirsutism, and menstrual disorders), exposure to progestogen only oral contraceptives, non-oral contraceptives (progestogen only and combined), and recency and duration of use for combined oral contraceptives. We combined the results from the imputed sets using Rubin's rules. ${ }^{33}$

To facilitate comparison of our results with those from earlier studies, which had analysed the associations of exposure to combined oral contraceptives by reference to levonorgestrel, we reran the analyses comparing current exposure to each drug of interest with current exposure to levonorgestrel (in combination with a normal oestrogen dose $(30-40 \mu \mathrm{g})$, the only doses prescribed in our data). Current exposures to levonorgestrel and the drug of interest were replaced with a variable coded as exposure to the drug, no exposure to the drug, and exposure to levonorgestrel. Analyses were adjusted for past exposure to levonorgestrel and the drug of interest, exposure to other combined oral contraceptives, and confounding factors.

We ran three additional analyses to look at methodological issues and allow comparisons with other published studies. Because results of diagnostic tests for VTE are not generally included in the primary care electronic records, some studies ${ }^{11} 14$ used subsequent anticoagulation therapy to confirm VTE diagnosis, including only patients treated as such despite possible under ascertainment of VTE cases. In our study, anticoagulation records were available only for prescriptions in primary care, representing doctors' initial responses to patients presenting with VTE symptoms rather than a more complete record of initial and subsequent treatments. However, to facilitate comparison with these studies, we ran another analysis on VTE cases, supported with either prescriptions for anticoagulation therapy (BNF 2.8.2) or records of death within six weeks of the recorded date of VTE diagnosis. Links to individual mortality data from the ONS were available for all QResearch practices, so these were included in identification of deaths due to VTE. This was not the case for CPRD practices, however, so identification of deaths for the CPRD analysis was derived solely from the general practitioner record.

To distinguish whether there are different associations in idiopathic cases compared with non-idiopathic cases, an additional stratified analysis was run on subgroups of cases and matched controls. In this analysis, idiopathic cases were first analysed with any idiopathic matched controls (that is, controls with none of the chronic conditions or events listed above). Then, only non-idiopathic cases were analysed with any non-idiopathic matched controls (that is, controls with one or more of the chronic conditions or events used to identify non-idiopathic cases). The third analysis was run on subgroups of younger (15-24 years) and older (25-49 years) women, because younger women are more likely to use contraceptive clinics as a source of oral contraceptives, potentially leading to a lack of recorded exposure data for this group. ${ }^{30}$

In the protocol, we had proposed a sensitivity analysis for practices linked to hospital admission data, where VTE cases would be identified not only from the practice records but also from hospital admissions data. For QResearch, because the selection process used linked data sources including hospital admissions, this additional analysis became redundant. Instead, we ran a sensitivity analysis using QResearch cases identified only through general practice medical records and matched controls. For CPRD, we ran the proposed sensitivity analysis for data from the subset of practices linked to both hospital admission data and ONS mortality data, where data from all sources were used to identify VTE cases. VTE cases in hospital admission and ONS mortality data were identified by ICD-10 codes (web table 1).

To increase the power of the study and obtain more precise estimates, we combined results from the two databases using a meta-analysis technique. Adjusted odds ratios from the conditional logistical regression analyses of the two datasets were pooled by use of a fixed effect model with inverse variance weights. ${ }^{34}$ We chose a fixed effect model because-apart from the necessarily different approaches to identification of relevant cases described above-the studies in CPRD and QResearch (which have similar sizes and similar methods of recording information) were comparable, using the same exclusion criteria, definitions of exposures and confounders, and the same models. In view of these similarities, differences in observed associations seemed most likely to derive from sampling variations, but we also ran a sensitivity analysis using a random effect model to allow for any heterogeneity. 
To estimate the magnitude of VTE risk associated with combined oral contraceptives, we calculated the numbers needed to harm per year by using the adjusted odds ratios derived from the combined analyses. ${ }^{35}$ The incidence for the unexposed female population could not be derived either from QResearch or CPRD because exposure details were not available for the whole cohorts. The rate was, therefore, derived from a Danish cohort ${ }^{12}$ taking into account the differences in study design. We based our calculations for numbers needed to harm on the adjusted odds ratios from the combined analyses for current use and the Danish study rates of 4.18 per 10000 women years for women aged 15-49 years and 4.91 per 10000 women years for those aged 25-49 years. We also estimated the number of additional VTE cases expected per year per 10000 treated women.

We used Stata version 13 for the analyses. All available cases were used from both QResearch and CPRD. A 1\% level of statistical significance was used to account for multiple comparisons and 95\% confidence intervals to enhance comparability with other studies. For clarity, only odds ratios from the combined analyses are presented and discussed, but the contributing odds ratios from CPRD and QResearch can be found in the tables.

\section{Results}

We identified 7334 incident VTE cases from CPRD based on clinical Read codes recorded in the general practitioner data, and 8211 incident VTE cases from QResearch within the study period, both with at least one year of medical records. Crude incidence of VTE cases per 10000 women years was 5.9 (95\% confidence interval 5.7 to 6.0) in CPRD and 6.1 (6.0 to 6.3) in QResearch. After matching cases to controls and removing ineligible participants, the final analysis included 5062 (69\%) VTE cases from CPRD matched to 19638 controls, and 5500 (67\%) VTE cases from QResearch matched to 22396
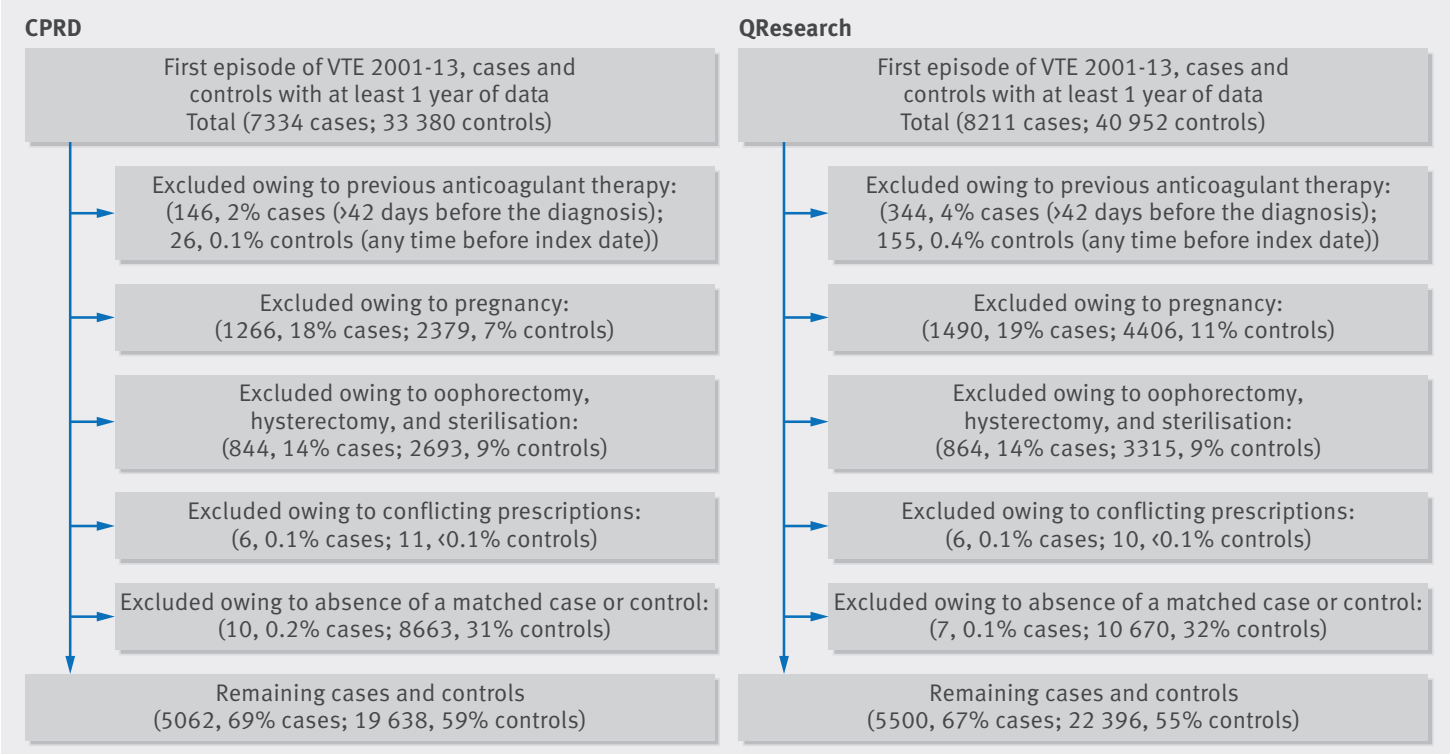

Fig 1 | Flow of included patients for CPRD and QResearch analyses with proportions of excluded observations at each point of exclusion
QResearch

controls (fig 1). Of 5500 VTE cases from QResearch, 5088 (93\%) were identified from primary care records, and an additional 284 (5\%) from hospital admission data and 128 (2\%) from ONS mortality data. For CPRD cases, 2917 (58\%) VTE events were recorded as deep vein thrombosis only; $1626(32 \%)$ as pulmonary embolism, with or without deep vein thrombosis; and 519 (10.3\%) as other types of VTE; corresponding numbers for QResearch cases were 3156 (57\%), 1613 (29\%), and 731 (13\%).

Proportions of cases and controls across the demographic measures and morbidities relevant to the study showed the similarities between database populations (table 1, web table 2). Median ages of women in the study were 38 years (interquartile range 30-44) for CPRD and 39 years (31-44) for QResearch. Current smoking was more common in cases than controls $(27 \% \mathrm{v}$ $21 \%$ for both databases), as was obesity (body mass index $\geq 30$; 30\% v 17\% for CPRD, 24\% v 14\% for QResearch). Proportions of women with established risk factors for VTE (that is, non-idiopathic cases and controls) were similar for each database ( $47 \%$ cases and 27\% controls for CPRD, 47\% and 26\% for QResearch). About half of women with VTE in the study had anticoagulation prescriptions or died within six weeks of the recorded diagnosis date (2454 and 79 cases, respectively, or 50\% overall in CPRD; 2749 and 207, or 54\% overall in QResearch).

\section{Exposure, main analysis}

Age standardised rates of exposure to any oral contraceptive did not change over the study period (overall rates 29\% in CPRD, 26\% in QResearch). Use of levonorgestrel, the most common combined oral contraceptive, decreased during the study (from $15 \%$ to $11 \%$ in CPRD, and $13 \%$ to $10 \%$ in QResearch), whereas use of progestogen only oral contraceptives rose from $3 \%$ to $7 \%$ (fig 2). 


\begin{tabular}{|c|c|c|c|c|}
\hline & \multicolumn{2}{|l|}{ CPRD } & \multicolumn{2}{|l|}{ QResearch } \\
\hline & Cases $(n=5062)$ & Controls $(n=19638)$ & Cases $(n=5500)$ & Controls $(n=22396)$ \\
\hline \multicolumn{5}{|l|}{ Age band at index date } \\
\hline $15-24$ years & $12.6(636)$ & $12.7(2496)$ & $9.0(493)$ & $9.5(2135)$ \\
\hline $25-34$ years & $25.5(1290)$ & $23.8(4666)$ & $25.9(1423)$ & $25.0(5589)$ \\
\hline $35-39$ years & $17.1(867)$ & $17.5(3433)$ & $18.0(992)$ & $17.7(3957)$ \\
\hline 40-44 years & $20.8(1055)$ & $21.9(4292)$ & $22.5(1239)$ & $23.3(5219)$ \\
\hline $45-49$ years & $24.0(1214)$ & $24.2(4751)$ & $24.6(1353)$ & $24.5(5496)$ \\
\hline \multicolumn{5}{|l|}{ Ethnic group } \\
\hline White & $36.0(1821)$ & $33.4(6561)$ & $61.6(3386)$ & $57.6(12900)$ \\
\hline Not recorded* & $60.2(3049)$ & $62.4(12249)$ & $29.5(1620)$ & $32.7(7316)$ \\
\hline Black & $1.6(79)$ & $1.2(237)$ & $4.2(233)$ & $3.0(680)$ \\
\hline Asian & $1.3(68)$ & $1.9(375)$ & $2.4(134)$ & $4.5(1013)$ \\
\hline Other & $0.9(45)$ & $1.1(216)$ & $2.3(127)$ & $2.2(487)$ \\
\hline \multicolumn{5}{|l|}{ Body mass index } \\
\hline $15-24$ & $34.6(1753)$ & $44.7(8774)$ & $34.6(1903)$ & $44.2(9895)$ \\
\hline $25-29$ & $22.6(1142)$ & $22.0(4317)$ & $21.9(1202)$ & $20.0(4473)$ \\
\hline$\geq 30$ & $30.3(1534)$ & $17.1(3353)$ & $24.2(1331)$ & $14.3(3196)$ \\
\hline Not recorded & $12.5(633)$ & $16.3(3194)$ & $19.3(1064)$ & $21.6(4832)$ \\
\hline \multicolumn{5}{|l|}{ Smoking status } \\
\hline Non-smoker & $51.1(2586)$ & $54.2(10645)$ & $43.5(2392)$ & $46.5(10410)$ \\
\hline Ex-smoker & $17.5(884)$ & $16.8(3295)$ & $23.3(1280)$ & $22.1(4952)$ \\
\hline Current light smoker & $6.3(319)$ & $6.0(1188)$ & $14.4(790)$ & $12.1(2703)$ \\
\hline Current moderate smoker & $14.4(730)$ & $11.2(2194)$ & $7.7(424)$ & $6.4(1433)$ \\
\hline Current heavy smoker & $6.6(334)$ & $4.2(828)$ & $4.5(248)$ & $2.8(621)$ \\
\hline Not recorded & $4.1(209)$ & 7.6 (1488) & $6.7(366)$ & $10.2(2277)$ \\
\hline \multicolumn{5}{|l|}{ Alcohol use } \\
\hline No use & $20.0(1014)$ & $17.9(3516)$ & $22.2(1220)$ & $19.3(4315)$ \\
\hline Ex-use & $6.0(303)$ & $4.4(869)$ & $6.7(367)$ & $5.3(1177)$ \\
\hline Light ( $\leq 2$ units/day) & $49.0(2479)$ & $50.5(9921)$ & $32.1(1766)$ & $32.9(7365)$ \\
\hline Moderate/heavy ( $\geq 3$ units/day) & $5.0(254)$ & $5.0(986)$ & $17.6(970)$ & $18.6(4173)$ \\
\hline Not recorded & $20.0(1012)$ & $22.1(4346)$ & $21.4(1177)$ & $24.0(5366)$ \\
\hline \multicolumn{5}{|l|}{ Non-idiopathic cases } \\
\hline Proportion (no) of cases or controls & $47.0(2380)$ & $27.2(5340)$ & $46.9(2582)$ & $26.3(5891)$ \\
\hline \multicolumn{5}{|l|}{ Comorbidities } \\
\hline Asthma & $19.1(969)$ & $12.9(2530)$ & $18.8(1036)$ & $12.0(2693)$ \\
\hline Congestive cardiac disease & $0.4(20)$ & $0.0(5)$ & $0.2(13)$ & $0.0(5)$ \\
\hline Rheumatoid arthritis & $1.5(75)$ & $0.6(121)$ & $2.2(123)$ & $0.8(187)$ \\
\hline Systemic lupus erythematosus & $0.5(27)$ & $0.1(22)$ & $0.6(35)$ & $0.1(25)$ \\
\hline Renal disease & $0.9(48)$ & $0.2(35)$ & $1.1(62)$ & $0.3(65)$ \\
\hline Stroke & $0.9(44)$ & $0.1(22)$ & $0.9(50)$ & $0.2(48)$ \\
\hline Chronic obstructive pulmonary disease & $0.5(26)$ & $0.2(30)$ & $0.6(32)$ & $0.1(31)$ \\
\hline Coronary vascular disease & $1.0(52)$ & $0.3(50)$ & $1.5(82)$ & $0.3(77)$ \\
\hline Coagulation disturbances & $0.2(11)$ & $0.0(9)$ & $0.2(13)$ & $0.0(6)$ \\
\hline Varicose veins & $2.8(143)$ & $1.6(314)$ & $2.7(151)$ & $1.6(359)$ \\
\hline Hypertension & $6.3(319)$ & $3.6(698)$ & $6.0(329)$ & $3.7(831)$ \\
\hline Cancer & $6.6(333)$ & $0.9(180)$ & $6.6(363)$ & $0.9(204)$ \\
\hline Inflammatory bowel disease & $1.9(96)$ & $0.6(118)$ & $1.8(100)$ & $0.6(143)$ \\
\hline \multicolumn{5}{|l|}{ Conditions in previous 6 months } \\
\hline Infection & $19.0(964)$ & $10.4(2033)$ & $17.2(948)$ & $9.0(2026)$ \\
\hline Surgery or leg/hip fracture & $1.1(54)$ & $0.1(16)$ & $0.9(51)$ & $0.1(24)$ \\
\hline Hospital admission & $1.4(72)$ & $0.2(48)$ & $4.1(223)$ & $1.1(248)$ \\
\hline \multicolumn{5}{|c|}{ Indications for hormonal contraceptive use } \\
\hline Acne & $12.6(638)$ & $11.7(2307)$ & $9.3(514)$ & $8.6(1933)$ \\
\hline Menstrual disorders & $36.5(1847)$ & $31.0(6091)$ & $27.2(1497)$ & $23.0(5141)$ \\
\hline Hirsutism & $2.1(107)$ & $1.3(260)$ & $1.4(75)$ & $1.0(229)$ \\
\hline Polycystic ovary syndrome & $3.4(174)$ & $2.2(433)$ & $3.1(170)$ & $2.4(535)$ \\
\hline \multicolumn{5}{|c|}{ Contraceptive drug use in previous month } \\
\hline Any hormonal contraceptive & $32.6(1649)$ & $20.3(3996)$ & $33.4(1838)$ & $19.7(4418)$ \\
\hline Any oral combined contraceptive & $24.9(1259)$ & $14.4(2835)$ & $23.8(1309)$ & $12.6(2823)$ \\
\hline Any oral progestogen only & $5.1(260)$ & $4.4(866)$ & $5.1(281)$ & $4.0(907)$ \\
\hline Any non-oral hormonal contraceptive & $2.6(130)$ & $1.5(295)$ & $4.5(248)$ & $3.1(688)$ \\
\hline Switch in the last month & $1.9(95)$ & $0.6(110)$ & $1.9(103)$ & $0.5(123)$ \\
\hline
\end{tabular}



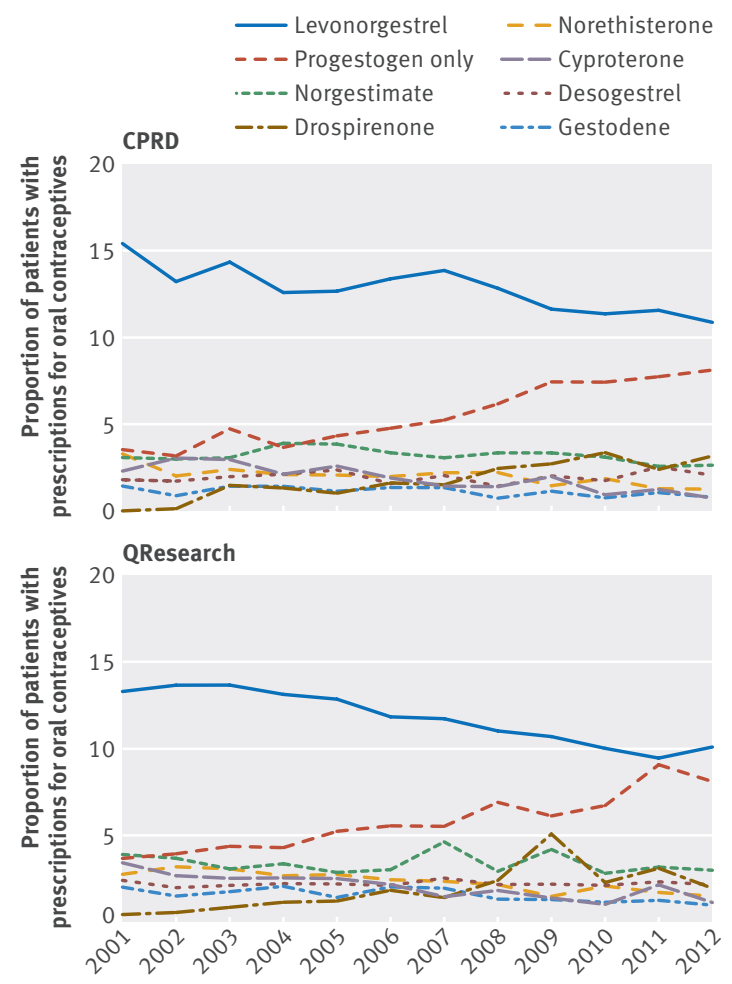

Year

Fig 2 Use of different types of oral contraceptives by year and database. Data are based on age standardised exposure in controls using the UK's general population

In the year before the index date, $30 \%$ of cases and $18 \%$ of controls in CPRD had at least one prescription for combined oral contraceptives. For QResearch, the numbers were $28 \%$ of cases and $16 \%$ of controls. Preparations with levonorgestrel seemed to be the most commonly prescribed combined oral contraceptives ( $45 \%$ of exposed cases, $54 \%$ of exposed controls in CPRD; 44\%, $52 \%$ in QResearch). Other contraceptive types were much less used (all between 7\% and 13\%). Most users of combined oral contraceptives within the previous year were current users-that is, exposed in the last 28 days (84\% of exposed cases, $79 \%$ of exposed controls in CPRD; 84\%, 77\% in QResearch; web table 3). Most of the current users were exposed for more than 84 days (across different permutations of drug type, database, and cases and controls, all between $70 \%$ and $87 \%$ ).

For the analyses combining CPRD and QResearch results, current use of any combined oral contraceptive was associated with a significantly increased VTE risk (adjusted odds ratio 2.97, 95\% confidence interval 2.78 to 3.17) compared with no exposure in the last year. The risks varied between different types of oral contraceptives and resulted in two clear groups: norethisterone, levonorgestrel, and norgestimate in one group; and desogestrel, gestodene, drospirenone, and cyproterone in the other. Current exposure showed that the first group had a two and a half times increased VTE risk (levonorgestrel (2.38, 2.18 to 2.59), norethisterone (2.56, 2.15 to 3.06), and norgestimate (2.53, 2.17 to 2.96 ), and roughly a four times increased risk for the second group (desogestrel (4.28, 3.66 to 5.01$)$, gestodene $(3.64,3.00$ to 4.43$)$, drospirenone (4.12, 3.43 to 4.96), and cyproterone (4.27, 3.57 to 5.11) all compared to no exposure in the last year (table 2, fig 3, web table 4 for all variables in the model).

In our analysis to facilitate comparison with existing studies, risks associated with current use of norethisterone and norgestimate did not differ significantly from levonorgestrel. However, the risk associated with current use of gestodene was 1.5 times higher than for levonorgestrel (adjusted odds ratio 1.52, 95\% confidence interval 1.24 to 1.87 ) and about 1.8 times higher for desogestrel, drospirenone, and cyproterone (table 3).

\begin{tabular}{|c|c|c|c|c|c|c|}
\hline \multirow[b]{2}{*}{ Type of contraceptive } & \multicolumn{2}{|l|}{ CPRD } & \multicolumn{2}{|l|}{ QResearch } & \multicolumn{2}{|l|}{ Combined analysis } \\
\hline & $\begin{array}{l}\text { No of cases/ } \\
\text { controls }\end{array}$ & $\begin{array}{l}\text { Adjusted odds } \\
\text { ratio }(95 \% \mathrm{CI})^{*}\end{array}$ & $\begin{array}{l}\text { No of cases/ } \\
\text { controls }\end{array}$ & $\begin{array}{l}\text { Adjusted odds } \\
\text { ratio }(95 \% \mathrm{Cl})^{*}\end{array}$ & $\begin{array}{l}\text { Pooled odds } \\
\text { ratio }(95 \% \mathrm{Cl})\end{array}$ & $\mathbf{P}$ \\
\hline Total No & $5062 / 19638$ & - & $5500 / 22396$ & - & - & - \\
\hline No use in previous year (reference) & - & 1.00 & - & 1.00 & 1.00 & - \\
\hline \multicolumn{7}{|l|}{ Current use } \\
\hline Norethisterone & $96 / 245$ & 2.30 (1.78 to 2.99$)$ & $109 / 259$ & 2.82 (2.21 to 3.60$)$ & $2.56(2.15$ to 3.06$)$ & $<0.001$ \\
\hline Levonorgestrel & $521 / 1451$ & 2.23 (1.97 to 2.52$)$ & $540 / 1411$ & 2.52 (2.24 to 2.84$)$ & 2.38 (2.18 to 2.59$)$ & $<0.001$ \\
\hline Norgestimate & $122 / 370$ & 1.96 (1.56 to 2.46$)$ & $160 / 352$ & $3.15(2.56$ to 3.89$)$ & $2.53(2.17$ to 2.96$)$ & $<0.001$ \\
\hline Desogestrel & $165 / 228$ & 4.43 (3.54 to 5.55$)$ & $163 / 262$ & 4.15 (3.34 to 5.15$)$ & 4.28 (3.66 to 5.01$)$ & $<0.001$ \\
\hline Gestodene & $78 / 149$ & $3.14(2.32$ to 4.24$)$ & $115 / 182$ & 4.07 (3.14 to 5.26$)$ & $3.64(3.00$ to 4.43$)$ & $<0.001$ \\
\hline Drospirenone & $139 / 200$ & $4.36(3.39$ to 5.60$)$ & $102 / 170$ & 3.86 (2.93 to 5.08$)$ & $4.12(3.43$ to 4.96$)$ & $<0.001$ \\
\hline Cyproterone & 138/192 & $4.13(3.22$ to 5.31$)$ & $120 / 187$ & $4.42(3.41$ to 5.73$)$ & 4.27 (3.57 to 5.11$)$ & $<0.001$ \\
\hline \multicolumn{7}{|l|}{ Different doses of oestrogen } \\
\hline Norethisterone $20 \mu \mathrm{g}$ & $44 / 94$ & 2.94 (2.00 to 4.34$)$ & $36 / 79$ & 2.72 (1.78 to 4.16$)$ & 2.84 (2.13 to 3.78$)$ & $<0.001$ \\
\hline Norethisterone $30 / 40 / 50 \mu \mathrm{g}$ & $52 / 151$ & 1.93 (1.36 to 2.72$)$ & $73 / 180$ & 2.87 (2.14 to 3.84 ) & 2.43 (1.94 to 3.03 ) & $<0.001$ \\
\hline Desogestrel $20 \mu \mathrm{g}$ & $57 / 88$ & 4.43 (3.08 to 6.37$)$ & $60 / 97$ & $3.80(2.68$ to 5.41$)$ & 4.10 (3.18 to 5.28) & $<0.001$ \\
\hline Desogestrel $30 / 40 \mu \mathrm{g}$ & $108 / 140$ & $4.42(3.34$ to 5.85$)$ & $103 / 165$ & $4.36(3.33$ to 5.71$)$ & 4.39 (3.62 to 5.33$)$ & $<0.001$ \\
\hline Gestodene $20 \mu \mathrm{g}$ & $17 / 22$ & 4.70 (2.41 to 9.14$)$ & $22 / 25$ & $5.54(2.99$ to 10.28$)$ & 5.13 (3.26 to 8.07$)$ & $<0.001$ \\
\hline Gestodene 30/40 $\mu \mathrm{g}$ & $61 / 127$ & $2.86(2.05$ to 4.00$)$ & $93 / 157$ & 3.83 (2.89 to 5.08$)$ & $3.40(2.74$ to 4.21$)$ & $<0.001$ \\
\hline
\end{tabular}

*Adjusted for body mass index, smoking status, alcohol consumption, ethnic group, chronic and acute conditions, and use of other hormonal contraceptives. 
Type of contraceptive

Adjusted odds ratio

$(95 \% \mathrm{Cl})$

Norethisterone

CPRD

QResearch

Subtotal: $P=0.267, I^{2}=18.8 \%$

Levonorgestrel

CPRD

QResearch

Subtotal: $P=0.166, I^{2}=47.9 \%$

Norgestimate

CPRD

QResearch

Subtotal: $P=0.003, I^{2}=88.9 \%$

Desogestrel

CPRD

QResearch

Subtotal: $P=0.676, I^{2}=0 \%$

Gestodene

CPRD

QResearch

Subtotal: $P=0.198, I^{2}=39.7 \%$

Drospirenone

CPRD

QResearch

Subtotal: $P=0.519, I^{2}=0 \%$

Cyproterone

CPRD

QResearch

Subtotal: $P=0.713, I^{2}=0 \%$

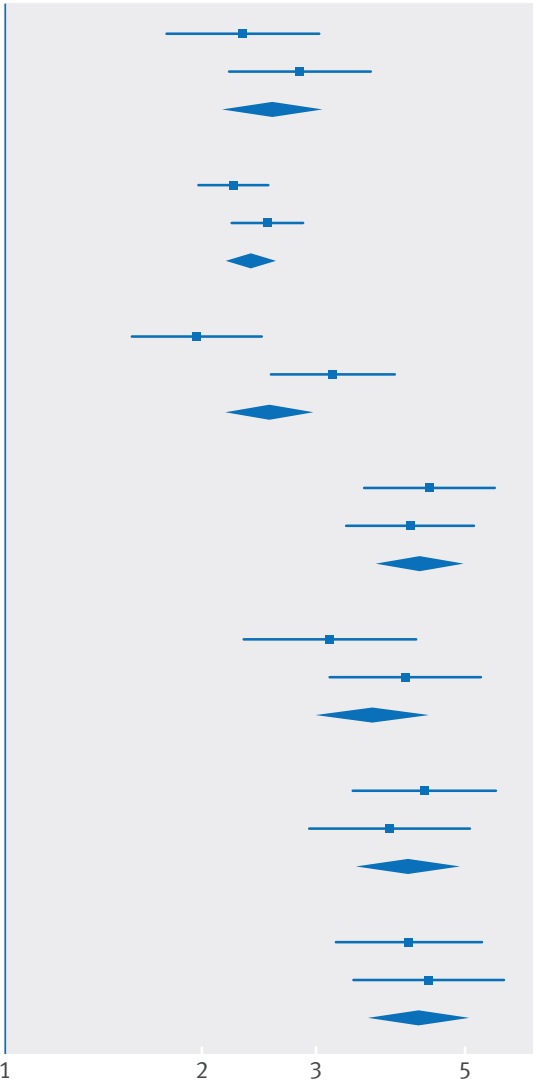

Adjusted odds ratio $(95 \% \mathrm{CI})$

2.82 (2.21 to 3.60$)$

2.56 (2.15 to 3.06$)$

2.23 (1.97 to 2.52 )

2.52 (2.24 to 2.84 )

2.38 (2.18 to 2.59 )

1.96 (1.56 to 2.46$)$

3.15 (2.56 to 3.89 )

2.53 (2.17 to 2.96 )

4.43 (3.54 to 5.55$)$

4.15 (3.34 to 5.15$)$

4.28 (3.66 to 5.01 )

3.14 (2.32 to 4.24)

4.07 (3.14 to 5.26 )

3.64 (3.00 to 4.43 )

4.36 (3.39 to 5.60$)$

3.86 (2.93 to 5.08 )

4.12 (3.43 to 4.96 )

4.13 (3.22 to 5.31)

4.42 (3.41 to 5.73 )

4.27 (3.57 to 5.11 )
2.30 (1.78 to 2.99$)$

Fig 3 Adjusted odds ratio for VTE in patients currently exposed to combined oral contraceptives compared with no use in the last year, by database. Odds ratios and $95 \%$ confidence intervals are adjusted for body mass index, smoking status, alcohol consumption, ethnic group, chronic and acute conditions, and use of other hormonal contraceptives compared with long term users (adjusted odds ratios 3.38 (95\% confidence interval 2.86 to 3.99$)$ v 2.16 (1.97 to 2.38$), \mathrm{P}<0.001)$. For other drug types, the results were inconsistent, with odds ratios for shorter exposure marginally higher for norethisterone and gestodene, but marginally lower for norgestimate, desogestrel, drospirenone, and cyproterone (web table 5). Adjusted odds ratios for other confounders, including use of other hormonal contraceptives (oral progestogen only and non-oral hormonal treatments) and associations for our category of past use, are available in web table 4.

Although previous studies have not shown any confounding effect from body mass index, ${ }^{11}$ we found that inclusion of body mass index into the model changed odds ratios for drug exposures by percentages ranging from $7 \%$ to over $10 \%$, with the highest effect for drospirenone (web table 6). Each risk factor, when included individually, did not show a major effect on the results for drug exposures. But when all combined, the odds ratios for drug exposures changed by percentages of between $13 \%$ and $25 \%$ compared with the unadjusted values. Adjustment for deprivation information in QResearch changed odds ratios for exposures by up to $5 \%$.

\section{Additional analyses}

When restricted to cases with anticoagulation prescriptions and matched controls, the overall pattern of risks was similar to those from the main analysis (table 4), although odds ratios were higher for all combined oral contraceptive drug types within a wide range of relative change. The differences were smaller for norethisterone ( $8 \%$ increase in adjusted odds ratio) and levonorgestrel (24\%), and larger for norgestimate (40\%), gestodene (78\%), desogestrel (46\%), drospirenone (48\%), and cyproterone (40\%). However, when tabulated by exposure, the variations shown in proportions of cases with anticoagulation prescriptions for different exposure groups (web table 7) might reflect some differential treatment of patients at initial presentation based on known drug risks.

The analysis for idiopathic cases (that is, with no risk associated conditions) and matched controls showed higher odds ratios for the oral contraceptives in the idiopathic analysis than the main analysis (table 4), but odds ratios by type of oral contraceptive were similar to the main analysis results. The odds ratios for the non-idiopathic group were correspondingly smaller (web table

\begin{tabular}{|c|c|c|c|c|c|c|}
\hline \multirow[b]{2}{*}{ Drug name } & \multicolumn{2}{|l|}{ CPRD } & \multicolumn{2}{|l|}{ QResearch } & \multicolumn{2}{|l|}{ Combined analysis } \\
\hline & Adjusted odds ratio $(95 \% \mathrm{CI})^{*}$ & $\mathbf{P}$ & Adjusted odds ratio $(95 \% \mathrm{CI})^{*}$ & $P$ & Adjusted odds ratio $(95 \% \mathrm{CI})$ * & $P$ \\
\hline Levonorgestrel & 1.00 & - & 1.00 & - & 1.00 & - \\
\hline Norethisterone & 1.03 (0.78 to 1.36$)$ & 0.8 & $1.12(0.86$ to 1.45$)$ & 0.4 & 1.08 (0.89 to 1.30$)$ & 0.4 \\
\hline Norgestimate & 0.88 (0.69 to 1.12$)$ & 0.3 & 1.25 (1.00 to 1.57$)$ & 0.05 & $1.06(0.90$ to 1.26$)$ & 0.5 \\
\hline Desogestrel & 1.99 (1.56 to 2.54$)$ & $<0.001$ & 1.65 (1.30 to 2.08$)$ & $<0.001$ & 1.80 (1.52 to 2.13$)$ & $<0.001$ \\
\hline Gestodene & 1.41 (1.03 to 1.93$)$ & 0.03 & 1.61 (1.23 to 2.12$)$ & $<0.001$ & 1.52 (1.24 to 1.87$)$ & $<0.001$ \\
\hline Drospirenone & 1.95 (1.50 to 2.55$)$ & $<0.001$ & 1.53 (1.15 to 2.04$)$ & 0.004 & 1.75 (1.43 to 2.12$)$ & $<0.001$ \\
\hline Cyproterone & $1.85(1.42$ to 2.41$)$ & $<0.001$ & $1.76(1.34$ to 2.31$)$ & $<0.001$ & 1.80 (1.49 to 2.18$)$ & $<0.001$ \\
\hline
\end{tabular}




\begin{tabular}{|c|c|c|c|c|c|c|}
\hline \multirow[b]{2}{*}{ Type of contraceptive } & \multicolumn{2}{|l|}{ CPRD } & \multicolumn{2}{|l|}{ QResearch } & \multicolumn{2}{|l|}{ Combined analysis } \\
\hline & $\begin{array}{l}\text { No of cases/ } \\
\text { controls }\end{array}$ & $\begin{array}{l}\text { Adjusted odds ratio } \\
(95 \% \mathrm{Cl})^{*}\end{array}$ & $\begin{array}{l}\text { No of cases/ } \\
\text { controls }\end{array}$ & $\begin{array}{l}\text { Adjusted odds ratio } \\
(95 \% \mathrm{Cl})^{*}\end{array}$ & $\begin{array}{l}\text { Pooled odds ratio } \\
(95 \% \mathrm{Cl})\end{array}$ & $\mathbf{P}$ \\
\hline \multicolumn{7}{|c|}{ Women treated with anticoagulants } \\
\hline Total No & $2533 / 9882$ & - & 2956/11933 & - & - & - \\
\hline No use in previous year & - & 1.00 & - & 1.00 & 1.00 & - \\
\hline \multicolumn{7}{|l|}{ Current use } \\
\hline Norethisterone & $52 / 131$ & $2.70(1.88$ to 3.87$)$ & $57 / 143$ & $2.82(2.00$ to 3.97$)$ & $2.76(2.16$ to 3.54$)$ & $<0.001$ \\
\hline Levonorgestrel & $260 / 683$ & 2.82 (2.36 to 3.38$)$ & $297 / 739$ & 3.06 (2.59 to 3.61$)$ & 2.95 (2.61 to 3.33$)$ & $<0.001$ \\
\hline Norgestimate & $71 / 181$ & $2.52(1.84$ to 3.46$)$ & $99 / 176$ & $4.68(3.51$ to 6.24$)$ & 3.53 (2.86 to 4.37$)$ & $<0.001$ \\
\hline Desogestrel & $113 / 113$ & 7.37 (5.41 to 10.0$)$ & $95 / 132$ & 5.32 (3.95 to 7.17$)$ & 6.23 (5.03 to 7.72$)$ & $<0.001$ \\
\hline Gestodene & $57 / 61$ & 6.89 (4.56 to 10.4$)$ & $82 / 92$ & $6.20(4.43$ to 8.67$)$ & 6.47 (4.98 to 8.39$)$ & $<0.001$ \\
\hline Drospirenone & $94 / 108$ & 6.03 (4.32 to 8.41$)$ & $63 / 76$ & 6.17 (4.20 to 9.05) & 6.09 (4.73 to 7.83$)$ & $<0.001$ \\
\hline Cyproterone & $83 / 99$ & 5.64 (3.99 to 7.97$)$ & $73 / 95$ & $6.36(4.45$ to 9.08$)$ & $5.98(4.66$ to 7.66$)$ & $<0.001$ \\
\hline \multicolumn{7}{|l|}{ Idiopathic cases/controls } \\
\hline Total No & $2630 / 7632$ & - & $2871 / 8937$ & - & - & - \\
\hline No use in previous year & - & 1.00 & - & 1.00 & 1.00 & - \\
\hline \multicolumn{7}{|l|}{ Current use } \\
\hline Norethisterone & $57 / 96$ & 2.55 (1.78 to 3.66$)$ & $74 / 117$ & 3.08 (2.24 to 4.24$)$ & 2.84 (2.23 to 3.60$)$ & $<0.001$ \\
\hline Levonorgestrel & $321 / 555$ & $2.70(2.28$ to 3.19$)$ & $333 / 602$ & 2.89 (2.46 to 3.39$)$ & 2.80 (2.49 to 3.14$)$ & $<0.001$ \\
\hline Norgestimate & $72 / 163$ & 1.94 (1.43 to 2.64$)$ & $104 / 148$ & 3.64 (2.74 to 4.82$)$ & $2.73(2.22$ to 3.36$)$ & $<0.001$ \\
\hline Desogestrel & $107 / 100$ & 5.09 (3.75 to 6.91$)$ & $98 / 105$ & $4.73(3.50$ to 6.39$)$ & 4.90 (3.95 to 6.08$)$ & $<0.001$ \\
\hline Gestodene & $52 / 68$ & $3.42(2.28$ to 5.12$)$ & $66 / 72$ & 4.58 (3.20 to 6.58$)$ & $4.02(3.07$ to 5.27$)$ & $<0.001$ \\
\hline Drospirenone & $86 / 78$ & 4.91 (3.44 to 7.01 ) & $68 / 57$ & 5.61 (3.79 to 8.32 ) & 5.22 (4.01 to 6.79$)$ & $<0.001$ \\
\hline Cyproterone & $83 / 83$ & 4.77 (3.39 to 6.71$)$ & $66 / 79$ & 4.59 (3.19 to 6.61$)$ & 4.69 (3.65 to 6.01$)$ & $<0.001$ \\
\hline \multicolumn{7}{|l|}{ Women aged $15-24$ years } \\
\hline Total No & $636 / 2496$ & - & $493 / 2135$ & - & - & - \\
\hline No use in previous year & - & 1.00 & - & 1.00 & 1.00 & - \\
\hline \multicolumn{7}{|l|}{ Current use } \\
\hline Norethisterone & $15 / 61$ & 1.10 (0.57 to 2.10$)$ & $16 / 39$ & 3.83 (1.94 to 7.57$)$ & 1.99 (1.24 to 3.18$)$ & 0.004 \\
\hline Levonorgestrel & $150 / 431$ & 2.42 (1.87 to 3.13$)$ & $88 / 314$ & 2.28 (1.66 to 3.13$)$ & 2.36 (1.93 to 2.89$)$ & $<0.001$ \\
\hline Norgestimate & $31 / 88$ & 2.25 (1.40 to 3.61$)$ & $36 / 76$ & $4.83(2.97$ to 7.84$)$ & 3.26 (2.32 to 4.58$)$ & $<0.001$ \\
\hline Desogestrel & $30 / 49$ & $4.37(2.57$ to 7.44$)$ & $24 / 49$ & $3.52(1.97$ to 6.29$)$ & 3.96 (2.67 to 5.86$)$ & $<0.001$ \\
\hline Gestodene & $11 / 24$ & 2.56 (1.14 to 5.73$)$ & $13 / 25$ & 4.67 (2.21 to 9.88$)$ & 3.53 (2.04 to 6.12$)$ & $<0.001$ \\
\hline Drospirenone & $38 / 64$ & $3.90(2.37$ to 6.40$)$ & $17 / 49$ & $2.69(1.40$ to 5.17$)$ & 3.41 (2.29 to 5.05$)$ & $<0.001$ \\
\hline Cyproterone & $37 / 63$ & $3.77(2.34$ to 6.07$)$ & $31 / 51$ & 4.95 (2.79 to 8.78$)$ & 4.21 (2.92 to 6.08$)$ & $<0.001$ \\
\hline \multicolumn{7}{|c|}{ Women aged $25-49$ years } \\
\hline Total No & $4426 / 17142$ & - & $5007 / 20261$ & - & - & - \\
\hline No use in previous year & - & 1.00 & - & 1.00 & 1.00 & - \\
\hline \multicolumn{7}{|l|}{ Current use } \\
\hline Norethisterone & $81 / 184$ & 2.75 (2.06 to 3.67 ) & $93 / 220$ & 2.73 (2.10 to 3.56$)$ & 2.74 (2.26 to 3.33$)$ & $<0.001$ \\
\hline Levonorgestrel & $371 / 1020$ & 2.16 (1.87 to 2.49$)$ & $452 / 1097$ & 2.63 (2.31 to 3.00$)$ & $2.40(2.18$ to 2.65$)$ & $<0.001$ \\
\hline Norgestimate & $91 / 282$ & $1.93(1.49$ to 2.51$)$ & $124 / 276$ & $2.92(2.31$ to 3.70$)$ & 2.43 (2.04 to 2.89$)$ & $<0.001$ \\
\hline Desogestrel & $135 / 179$ & 4.62 (3.59 to 5.93) & $139 / 213$ & 4.26 (3.37 to 5.40$)$ & $4.43(3.73$ to 5.26$)$ & $<0.001$ \\
\hline Gestodene & $67 / 125$ & 3.30 (2.38 to 4.57$)$ & $102 / 157$ & 4.03 (3.06 to 5.30$)$ & 3.71 (3.00 to 4.58) & $<0.001$ \\
\hline Drospirenone & 101/136 & 4.75 (3.53 to 6.38$)$ & $85 / 121$ & 4.37 (3.21 to 5.95$)$ & 4.56 (3.69 to 5.65$)$ & $<0.001$ \\
\hline Cyproterone & $101 / 129$ & 4.41 (3.28 to 5.93$)$ & $89 / 136$ & 4.31 (3.20 to 5.80$)$ & 4.36 (3.53 to 5.38$)$ & $<0.001$ \\
\hline
\end{tabular}

8), but not as reliable because fewer non-idiopathic controls were available to match to non-idiopathic cases, leading to a reduction of the original matching ratio of cases to controls from 1:5 to about 1:1.5.

In the analysis of VTE cases according to age group, the proportion of the younger group was small (15-24 years; 13\% in CPRD, 9\% in QResearch). Odds ratios were lower for this group than for the older group (25-49 years; table 4), but again the overall pattern of risk stayed in line with the main analysis.

Risks for combined oral contraceptives compared with levonorgestrel were consistent across all the additional analyses (table 5), with no significant differences for norethisterone and norgestimate. Odds ratios for other drugs ranged from 1.4 to 2.4 (all significant apart from some drugs in the non-idiopathic group and in the younger group, which were likely to be due to low numbers).

The results from CPRD and QResearch were similar with the exception of those for norgestimate. In the CPRD analyses, risks associated with norgestimate use were similar to risks for levonorgestrel, whereas in the QResearch analyses, risks for norgestimate consistently fell between those for levonorgestrel and desogestrel across all analyses. However, the combined 


\begin{tabular}{|c|c|c|c|c|c|c|}
\hline \multirow[b]{2}{*}{ Drug name } & \multicolumn{2}{|l|}{ CPRD } & \multicolumn{2}{|l|}{ QResearch } & \multicolumn{2}{|l|}{ Combined analysis } \\
\hline & $\begin{array}{l}\text { Adjusted odds ratio } \\
(95 \% \mathrm{CI})^{*}\end{array}$ & $P$ & $\begin{array}{l}\text { Adjusted odds ratio } \\
(95 \% \mathrm{CI})^{*}\end{array}$ & $\mathbf{P}$ & $\begin{array}{l}\text { Adjusted odds ratio } \\
(95 \% \mathrm{CI})^{*}\end{array}$ & $P$ \\
\hline \multicolumn{7}{|c|}{ Cases with anticoagulant prescription and matched controls } \\
\hline Levonorgestrel & 1.00 & - & 1.00 & - & 1.00 & - \\
\hline Norethisterone & 0.96 (0.65 to 1.41$)$ & 0.8 & $0.92(0.64$ to 1.33$)$ & 0.7 & $0.94(0.72$ to 1.22$)$ & 0.6 \\
\hline Norgestimate & 0.89 (0.64 to 1.26$)$ & 0.5 & 1.53 (1.12 to 2.09$)$ & 0.007 & 1.20 (0.95 to 1.51$)$ & 0.1 \\
\hline Desogestrel & 2.61 (1.87 to 3.65$)$ & $<0.001$ & 1.74 (1.26 to 2.41$)$ & $<0.001$ & 2.11 (1.68 to 2.67 ) & $<0.001$ \\
\hline Gestodene & 2.44 (1.58 to 3.77$)$ & $<0.001$ & 2.03 (1.42 to 2.90) & $<0.001$ & 2.19 (1.66 to 2.88$)$ & $<0.001$ \\
\hline Drospirenone & 2.14 (1.49 to 3.06$)$ & $<0.001$ & $2.02(1.35$ to 3.01$)$ & $<0.001$ & 2.08 (1.59 to 2.72 ) & $<0.001$ \\
\hline Cyproterone & 2.00 (1.38 to 2.89$)$ & $<0.001$ & 2.08 (1.43 to 3.03$)$ & $<0.001$ & 2.04 (1.57 to 2.65$)$ & $<0.001$ \\
\hline \multicolumn{7}{|c|}{ Idiopathic cases and controls } \\
\hline Levonorgestrel & 1.00 & - & 1.00 & - & 1.00 & - \\
\hline Norethisterone & 0.94 (0.64 to 1.39$)$ & 0.8 & $1.07(0.76$ to 1.50$)$ & 0.7 & $1.01(0.78$ to 1.30$)$ & 0.9 \\
\hline Norgestimate & 0.72 (0.52 to 1.00$)$ & 0.05 & 1.26 (0.93 to 1.71) & 0.1 & 0.97 (0.78 to 1.22$)$ & 0.8 \\
\hline Desogestrel & 1.88 (1.35 to 2.62$)$ & $<0.001$ & 1.64 (1.19 to 2.26$)$ & 0.003 & 1.75 (1.39 to 2.21$)$ & $<0.001$ \\
\hline Gestodene & 1.27 (0.83 to 1.94$)$ & 0.3 & 1.59 (1.09 to 2.33$)$ & 0.02 & 1.44 (1.08 to 1.91$)$ & 0.01 \\
\hline Drospirenone & $1.82(1.25$ to 2.65$)$ & 0.002 & 1.95 (1.29 to 2.94) & 0.002 & 1.88 (1.42 to 2.48$)$ & $<0.001$ \\
\hline Cyproterone & 1.77 (1.23 to 2.53$)$ & 0.002 & 1.59 (1.09 to 2.33$)$ & 0.02 & 1.68 (1.29 to 2.19$)$ & $<0.001$ \\
\hline \multicolumn{7}{|c|}{ Women aged $15-24$ years } \\
\hline Levonorgestrel & 1.00 & - & 1.00 & - & 1.00 & - \\
\hline Norethisterone & 0.45 (0.23 to 0.89$)$ & 0.02 & 1.68 (0.83 to 3.38$)$ & 0.1 & 0.85 (0.52 to 1.38$)$ & 0.5 \\
\hline Norgestimate & 0.93 (0.57 to 1.52$)$ & 0.8 & $2.12(1.27$ to 3.54$)$ & 0.004 & 1.38 (0.97 to 1.97$)$ & 0.08 \\
\hline Desogestrel & 1.81 (1.05 to 3.12$)$ & 0.03 & 1.54 (0.85 to 2.81$)$ & 0.2 & $1.68(1.12$ to 2.52$)$ & 0.01 \\
\hline Gestodene & 1.06 (0.47 to 2.40$)$ & 0.9 & 2.05 (0.94 to 4.44$)$ & 0.07 & 1.50 (0.85 to 2.63$)$ & 0.2 \\
\hline Drospirenone & 1.61 (0.96 to 2.70$)$ & 0.07 & 1.18 (0.60 to 2.33$)$ & 0.6 & 1.44 (0.95 to 2.17$)$ & 0.08 \\
\hline Cyproterone & $1.56(0.95$ to 2.56$)$ & 0.08 & 2.17 (1.19 to 3.96$)$ & 0.01 & 1.78 (1.21 to 2.62$)$ & 0.003 \\
\hline \multicolumn{7}{|c|}{ Women aged $25-49$ years } \\
\hline Levonorgestrel & 1.00 & - & 1.00 & - & 1.00 & - \\
\hline Norethisterone & $1.27(0.93$ to 1.74$)$ & 0.1 & 1.04 (0.78 to 1.38$)$ & 0.8 & $1.14(0.92$ to 1.40$)$ & 0.2 \\
\hline Norgestimate & 0.89 (0.67 to 1.19$)$ & 0.4 & 1.11 (0.86 to 1.44$)$ & 0.4 & 1.01 (0.83 to 1.22$)$ & 0.9 \\
\hline Desogestrel & 2.14 (1.62 to 2.82$)$ & $<0.001$ & $1.62(1.25$ to 2.10$)$ & $<0.001$ & $1.84(1.53$ to 2.23$)$ & $<0.001$ \\
\hline Gestodene & $1.53(1.08$ to 2.16$)$ & 0.02 & 1.53 (1.14 to 2.05$)$ & 0.004 & 1.53 (1.22 to 1.91$)$ & $<0.001$ \\
\hline Drospirenone & 2.20 (1.60 to 3.02$)$ & $<0.001$ & $1.66(1.20$ to 2.30$)$ & 0.002 & $1.92(1.53$ to 2.41$)$ & $<0.001$ \\
\hline Cyproterone & $2.04(1.49$ to 2.80$)$ & $<0.001$ & $1.64(1.20$ to 2.24$)$ & 0.002 & 1.83 (1.46 to 2.28$)$ & $<0.001$ \\
\hline
\end{tabular}

results, which gave more precise estimates, placed norgestimate in the group with levonorgestrel and norethisterone. An additional analysis for QResearch, which included adjustment for the Townsend deprivation score, showed results similar to the main analysis (web table 9).

\section{Sensitivity analyses}

When combining the results from the databases we discovered significant heterogeneity only for current use of norgestimate $\left(\mathrm{I}^{2}=89 \%, \mathrm{P}=0.003\right)$. The direction of the effect was the same in both databases and, after we applied a random effect model to combine the results, the estimate for norgestimate did not change our conclusion of its association being close to the estimates for the group of earlier contraceptives (combined odds ratio $2.49,95 \%$ confidence interval 1.56 to 3.97 ).

The sensitivity analysis for QResearch cases identified only through general practice medical records and matched controls delivered results in line with the main analysis (web table 10). The sensitivity analysis for CPRD practices linked to hospital admission and ONS mortality data was based on 346 general practices and covered the period between 1 January 2001 and 30 March 2012. The crude incidence of VTE per 10000 women years in this cohort was 5.7 (95\% confidence interval 5.5 to 5.8). We identified 436 extra cases from hospital admission data and 14 from ONS mortality data with at least one year of medical records. After exclusions, 2989 cases were included in the analysis, of which 2654 (89\%) were identified from general practice records, 324 (11\%) from hospital admission data, and 11 $(0.4 \%)$ from ONS mortality data. The results were also in line with the main analysis (web table 11).

\section{Numbers needed to harm and excess risk}

Because combined oral contraceptive use was associated with increased VTE risk, additional cases of VTE would be expected across all types of combined oral contraceptives in exposed women compared with unexposed women, and particularly in those aged 25-49 years (table 6). The lowest numbers of extra cases of VTE per year per 10000 treated women were six extra cases for levonorgestrel $(6,95 \%$ confidence interval 5 to 7$)$ and norgestimate (6, 5 to 8$)$ for women aged 15-49 years, and seven extra cases for levonorgestrel (7, 6 to 8) 
and norgestimate (7, 5 to 9) for those aged 25-49 years. The highest numbers of extra cases of VTE per year per 10000 treated women were for desogestrel (14 extra cases, 11 to 17$)$ and cyproterone $(14,11$ to 17$)$ for ages 15-49 years, and for drospirenone (17, 13 to 23), desogestrel (17, 13 to 21$)$, and cyproterone (17, 12 to 22$)$ for ages 25-49 years.

\section{Discussion}

In this observational study based on two large primary care databases, women exposed to drospirenone, gestodene, cyproterone, and desogestrel within the last 28 days had around a four times increased risk of VTE. Women exposed to levonorgestrel, norethisterone, and norgestimate had about two and a half times increase in VTE risk compared with women not exposed in the past year. Risks for current use of gestodene, drospirenone, cyproterone, and desogestrel were 1.5-1.8 times higher than for levonorgestrel. Results from the additional analyses stayed in line with the main findings, although there were stronger associations in the analyses restricted to cases with anticoagulant prescriptions and matched controls. These differences were expected and can be explained by our methodological approach. We saw no significant association in the analyses of oestrogen dosages.

\section{Strengths and limitations of the study}

The main strengths of this study are its recency, comprehensiveness, and generalisability. It was based on the general female population in the UK aged 15-49 years, and explored exposure to combined oral contraceptives commonly prescribed during the past 13 years. The study also benefitted from the statistical power of large samples from the two largest UK primary care databases. Consistency in records for diagnoses, lifestyle information, and prescriptions allowed us to combine the results from both databases and achieve narrower confidence intervals for our estimates. The study also benefitted from a consistent design.

Results were adjusted for several confounding factors such as body mass index, smoking status, alcohol use, and social deprivation, which were not available to some previous studies. Education and family history might also be considered to be confounders but neither could be included in the analysis because they are not recorded sufficiently often on either the QResearch or CPRD databases. Because the exposure was based on systematically recorded prescription information, the study was free from recall bias. All eligible women were included, thus eliminating selection bias. Several additional analyses looking at conflicting methodological issues from previous studies allow readers to compare and assess the validity of the results.

A study limitation was the potential misclassification of exposure to combined oral contraceptives. According to the Contraception and Sexual Health survey in Great Britain (2000-09), between 25\% and 28\% of women used an oral contraceptive depending on the year. ${ }^{36}$ Our data for both databases had similar age standardised rates of exposure to any oral contraceptive-26\% for QResearch and 29\% for CPRD. Because exposure information is based on prescriptions, however, there is a degree of uncertainty about actual use-when a woman started taking the drug or whether she took it at all. According to one survey from the United States, 19\% of women discontinued using oral contraceptives within the first six months, more commonly younger women. ${ }^{37}$ Because outcome information was collected prospectively, however, we do not see any reason why this effect should differ between cases and controls. Such misclassification of exposure might, however, shift odds ratios towards unity. Some uncertainty also relates to women who may have delayed use of drugs from past prescriptions (and so were actually current rather than past users), and to unaccounted residual risk associated with women who ceased use for any reason just before the current use period. However, these two potential misclassifications are likely to be small.

NHS community contraceptive clinics are also a source of oral contraceptive pills apart from general practice doctors. According to NHS Contraceptive Services reports issued between 2005 and 2013 (www.hscic.gov.uk), on average $6.9 \%$ of women under 25 years old and $1.6 \%$ of older women received oral contraceptive pills from contraceptive clinics. One report in 2005 released the numbers separately for combined and progestogen only pills, showing that the proportion of combined contraceptives prescribed was $91 \%$ of all oral contraceptives for younger women and $73 \%$ for older women. ${ }^{38}$ From these figures, we estimated that in the population, $6.3 \%$ of younger and $1.2 \%$ of older women had exposure to combined oral contraceptives without related general practice records. These women would appear in our analyses as not exposed, creating a potential underestimation that might

\begin{tabular}{|c|c|c|c|c|}
\hline \multirow[b]{2}{*}{ Use in previous year } & \multicolumn{2}{|c|}{ Numbers needed to harm over 1 year $(95 \% \mathrm{Cl})$} & \multicolumn{2}{|c|}{ Extra cases per 10000 treated per year $(95 \% \mathrm{Cl})$} \\
\hline & All ages $(15-49$ years)* & Age $25-49$ yearst & All ages $(15-49$ years)* & Age $25-49$ yearst \\
\hline Norethisterone & 1529 (1159 to 2086) & 1169 (874 to 1620$)$ & $7(5$ to 9$)$ & $9(6$ to 11$)$ \\
\hline Levonorgestrel & 1739 (1506 to 2028) & $1452(1237$ to 1723$)$ & $6(5$ to 7$)$ & 7 (6 to 8$)$ \\
\hline Norgestimate & 1561 (1223 to 2044) & 1428 (1077 to 1966) & $6(5$ to 8$)$ & $7(5$ to 9$)$ \\
\hline Desogestrel & 729 (597 to 899) & $594(478$ to 747$)$ & $14(11$ to 17$)$ & 17 (13 to 21$)$ \\
\hline Gestodene & 905 (697 to 1198) & $752(570$ to 1016$)$ & $11(8$ to 14$)$ & $13(10$ to 18$)$ \\
\hline Drospirenone & 766 (604 to 986) & 572 (438 to 758$)$ & $13(10$ to 17$)$ & 17 (13 to 23$)$ \\
\hline Cyproterone & 731 (582 to 932) & $606(465$ to 804$)$ & $14(11$ to 17$)$ & 17 (12 to 22$)$ \\
\hline
\end{tabular}


shift odds ratios towards unity, with an effect likely to be greater in the younger group.

The additional analyses for younger women did, in fact, produce lower odds ratios for all drugs apart from levonorgestrel and norgestimate. However, in the direct comparisons of different oral contraceptives with levonorgestrel, there was no potential bias with respect to misclassification of non-users because only oral contraceptive users were involved. Other biases could arise if the prescribing regimens of contraceptive clinics differed markedly from those of general practices (with one or other being more inclined towards higher risk, lower priced drugs), or if the material circumstances of women attending general practices differed from those attending contraceptive clinics. No published data seem to support this, however, and we believe that any such effects are likely to be negligible especially given the much higher proportion of supply from general practices.

There is also some degree of uncertainty in VTE diagnoses in both CPRD and QResearch practice records, because the results of diagnostic tests needed to confirm VTE are not generally available on the primary care databases. Furthermore, these diagnoses cannot be adjudicated in our study as might happen in a clinical trial, so may be subject to misclassification bias, with some false positives for cases and some false negatives for controls. The likelihood of misclassifications is, however, much higher for cases than controls because of the low incidence of VTE in the general population from which the controls are selected-therefore, overall, such errors and misclassifications if non-differential would tend to shift odds ratios towards unity.

Further, the incidence of VTE in our cohorts were both within the estimated range of five to 10 cases per 10000 person years for young women. ${ }^{39}$ The slightly higher rate within the QResearch cohort can be explained partly because the data used in the database's analysis was augmented by linked mortality information from the ONS and hospital episode statistics. This link will have added extra cases to the QResearch analysis and reduced diagnostic errors. However, the relatively small difference in rates between QResearch and CPRD, and the fact that the difference is also partly explained by the slightly higher median age of the QResearch cohort, suggests that neither analysis has been substantially affected by diagnostic errors. An earlier study has also shown that the addition of "possible" cases of VTE did not materially affect results obtained using only verified cases. ${ }^{40}$

Patients with a diagnosis of VTE are usually treated with anticoagulant medication. In our data, however, there are several reasons why VTE cases might not be followed by an anticoagulation prescription, such as a VTE event resulting in death, or treatment unrecorded in the GP record because it was initiated and continued in a hospital or other community setting. We found that, overall, about half of patients with VTE had a record of anticoagulation prescription within their general practice record. But a more detailed breakdown by exposure and drug type revealed possible differential treatment of exposed patients depending on contraceptive drug type and roughly reflecting the known VTE risks of the drugs.

The higher odds ratios in the additional analysis restricted to cases with anticoagulation prescriptions than those from the main analysis can be explained by a combination of the exclusion of uncertain events and differential anticoagulant prescribing by doctors. Women who receive anticoagulation treatment, which is necessary for VTE, are normally more likely to be true cases than those with no treatment recorded. Therefore, inclusion of some non-cases in our main analysis probably shifted odds ratios towards unity. On the other hand, our conjecture-based on evidence in our data of differential prescribing-is that doctors are more likely immediately to prescribe and record anticoagulants for patients with VTE symptoms exposed to a high risk oral contraceptive drug than for users of lower risk drugs. As a result, use of anticoagulation records to exclude uncertain events is more problematic in this study, and we would argue that results of our restricted analysis should be read with caution, indicating little more than a general agreement with earlier findings of increased odds ratios. In particular, the range of relative increases is probably exaggerated and comparisons between drug types possibly less reliable.

Finally, the higher odds ratios obtained from the subgroups with idiopathic cases and matched idiopathic controls, compared with odds ratios from the main analysis, were also expected because the absolute risk of VTE for unexposed patients is smaller in an idiopathic subgroup than that in a non-idiopathic subgroup (and by extension a general population). ${ }^{41}$ Although the associations seem to be stronger in the idiopathic analysis, we do not believe that they are necessarily generalisable because of the wide variation in definitions of idiopathic groups across existing studies, and the general difficulties that have been noted in defining such groups. ${ }^{42}$

\section{Comparison with recent studies}

In our study, we observed a reduction in prescription rates for combined oral contraceptives and an increased rate for progestogen only oral contraceptives. This is in line with NHS statistics for prescriptions in the community, and might reflect the effects of various guidelines and recommendations for patients at high risk of VTE. 43

Prior to our study, the largest study of VTE and combined oral contraceptives was a cohort study based on medical records from the Danish general population, covering the period 2001-09 and identifying 4246 women with a first recorded VTE. ${ }^{12}$ The Danish study adjusted for age, calendar year, and level of education. By comparison, our study had more than twice the number of VTE cases; added a further four years of data; adjusted for body mass index, smoking status, alcohol consumption, ethnic group, several chronic and acute conditions associated with increased VTE risk, and use of other hormonal contraceptives; and accounted for age, calendar year, and practice by matching. Not all types of combined contraceptives in the Danish study were available for comparison, 
because some are rarely prescribed in the UK. The most used contraceptives were levonorgestrel in the UK and gestodene in Denmark. In our main analysis, the odds ratios for current use of available contraceptives were similar to the Danish relative rates. Despite a difference in the proportion of cases with anticoagulant prescriptions (52\% in our study $v 67 \%$ in the Danish study), results in these subgroups were also similar.

The most recent CPRD based study focused on a comparison of VTE risk in idiopathic cases of VTE with anticoagulant prescriptions between levonorgestrel and drospirenone. ${ }^{14}$ It was run on records from 2002 to 2009 , and so was based on fewer practices than in our study. For current users, that study showed a threefold increase in VTE risk for drospirenone compared with levonorgestrel (17 v 44 exposed cases; odds ratio 3.3, 95\% confidence interval 1.4 to 7.6$)$. In our study, the odds ratios for current use of drospirenone were about twice as high as for levonorgestrel in our main analysis and all additional analyses. Another study (2002-08), ${ }^{11}$ based on pharmacological records from a US company and with a design similar to the recent CPRD study, ${ }^{14}$ had more women with VTE exposed to drospirenone than levonorgestrel (121 $v$ 65). It also showed an increased risk of VTE with drospirenone compared with levonorgestrel (odds ratio 2.4, 95\% confidence interval 1.7 to 3.4). Based on the same source of data (the same US company), ${ }^{11}$ another study showed a 70\% increased risk associated with desogestrel (1.7 (1.1 to 2.4)) and no significant increase with norgestimate, both compared to levonorgestrel. ${ }^{44}$ All three of these studies differed from ours in terms of case inclusion criteria, but their results align well with those from our additional analyses.

An Austrian case-control study (2002-06) ${ }^{45}$ investigated gestodene-containing and second generation oral contraceptives (79 and 83 exposed cases, respectively), identifying cases from referral centres and hospitals and deriving exposure information from questionnaires. Odds ratios for contraceptive use (with reference to non-users) were two to three times higher than in our study. But, as the authors suggested, this increased risk might be due to what they termed as "hospital bias," which can lead to overestimation of VTE risks. ${ }^{46}$ The study also compared gestodene with second generation pills but did not show any significant difference between the drugs in several sensitivity analyses. The relative differences between levonorgestrel and gestodene seen in our main and additional analysis for idiopathic cases were within the confidence interval or close to the upper confidence levels of this study.

A Dutch study (1999-2004) ${ }^{9}$ analysed all available oral contraceptives, identifying women with VTE from anticoagulation clinics and assessing exposure from postal questionnaires and interviews. Most controls were, however, acquired by random digit dialling, a technique that might have led to selective recruitment of a less active group with a poorer health profile than the general population. ${ }^{47}$ This technique and the higher response rates in women with VTE than in those controls (79\% v 64\%) might have introduced a selection bias and inflated odds ratios. In fact, the study did report higher odds ratios that those more generally reported elsewhere and consistently higher odds ratios with reference to non-use than our study, although relative differences with reference to levonorgestrel were again close to our findings.

An Israeli cohort study ${ }^{48}$ (2002-08) compared VTE risks for drospirenone with those for second and third generation oral contraceptives and found significant differences for drospirenone compared with both generations (rate ratio 1.65 (95\% confidence interval 1.02 to 2.65), 1.43 (1.15 to 1.78), respectively). The pattern of prescribing in this study was different from ours, with most common exposure to third generation drugs (384 exposed cases) and a lower use of levonorgestrel (23 exposed cases). Our study showed a similar association for current use of drospirenone compared with levonorgestrel (odds ratio of 1.75), but found no difference between drospirenone and third generation drugs.

Despite being a third generation drug, norgestimate (282 exposed cases) had associations with VTE risk similar to levonorgestrel in our study. But because norgestimate partly metabolises to levonorgestrel, ${ }^{49}$ its classification as a third generation drug is not clearly established. A Danish review classified norgestimate as a second generation drug and recommended prescribing it as a first choice contraceptive along with levonorgestrel and norethisterone. ${ }^{50}$ Norgestimate has a lower androgenic effect than levonorgestrel and had been used at a similar level to levonorgestrel in the Denmark study, ${ }^{12}$ although in our study levonorgestrel was prescribed three times more often than norgestimate. No significant difference between norgestimate and levonorgestrel was shown in the Danish study ${ }^{12}$ (165 exposed cases, rate ratio 1.18 (95\% confidence interval 0.86 to 1.62$)$ ) or in the US study ${ }^{44}$ (124, odds ratio 1.1 (95\% confidence interval 0.8 to 1.5$)$ ).

A meta-analysis ${ }^{16}$ including the Danish and US studies also demonstrated this non-difference between norgestimate and levonorgestrel, although it was not highlighted in the main study findings, which focused on different drug generations and oestrogen dosages. Although norgestimate had been on the market from 1995, other studies either did not consider norgestimate or were underpowered (for norgestimate, only five exposed cases in the Dutch study, ${ }^{9} 15$ in the CPRD study, ${ }^{4}$ and an unclear number in a German study with lower total numbers ${ }^{13}$ ).

Our study showed no associations between VTE risk and oestrogen dose for the three types of combined contraceptives, where this could be assessed. Levonorgestrel in the UK was prescribed mostly with a 30-40 $\mu \mathrm{g}$ dose of oestrogen, so oestrogen dose analysis was not possible. Comparable preparations for norethisterone have not been analysed before, so direct comparison of our results with other studies is not possible. A lower dose of oestrogen for desogestrel preparations was associated with a slightly lower risk of VTE, which was consistent with existing literature, ${ }^{12} 16$ but our difference was not significant. For combinations with gestodene, the numbers of current users were insufficient to draw any meaningful conclusions. 


\section{Conclusion}

This study, based on two large primary care databases, investigated risks of VTE associated with combined oral contraceptives prescribed to the general female population in the UK. We believe this study has the statistical power and sufficient adjustment for relevant confounders to be regarded as an important clarifying study, which has produced the most reliable possible risk estimates using currently available UK prescription data. It has confirmed results from other recent large scale studies and added new evidence, particularly for newer or less used combined oral preparations, such as those containing drospirenone or norgestimate. Risks associated with combined oral contraceptives were, apart from norgestimate, higher for newer drug preparations than for second generation drugs.

The results from our study and the Danish study ${ }^{12}$ provide evidence for relevant authorities concerned with prescribing guidelines or those involved with regulation of safety of medicines. In particular, along with the Danish study and a US study, ${ }^{44}$ our results confirm the similarity of risks for levonorgestrel and norgestimate in a UK context.

We acknowledge the contribution of Egton Medical Information System (EMIS) and the University of Nottingham for expertise in creating and maintaining QResearch and to the EMIS practices which contribute data; we thank CPRD and Vision Practices for allowing access to the CPRD for this study.

Contributors: JHC had the original idea for this study. CC contributed to the development of the idea and the study design. YV reviewed the literature, contributed to the study design, undertook the primary analysis as well as the first interpretation and wrote the first draft of the paper. JHC and CC critically reviewed the paper. All authors approved the submitted version.

Funding: This research received no external funding

Competing interests: All authors have completed the ICMJE uniform disclosure form at www.icmje.org/coi disclosure.pdf and declare: no support from any additional organisation for the submitted work; J HC is professor of clinical epidemiology at the University of Nottingham and unpaid director of QResearch, a not-for-profit organisation which is a joint partnership between the University of Nottingham and EMIS (commercial IT supplier for $60 \%$ of general practices in the UK); JHC is also a paid director of ClinRisk, which produces open and closed source software to ensure the reliable and updatable implementation of clinical risk algorithms within clinical computer systems to help improve patient care; no other relationships or activities that could appear to have influenced the submitted work.

Ethics and dissemination: The protocol for this study has been published in BMJ Open. It has also been independently peer reviewed by the QResearch Scientific Board and has been reported to Trent research ethics committee in accordance with the agreed procedure (reference no MREC/03/4/021). For CPRD data analysis, the protocol was approved by Independent Scientific Advisory Committee (reference no ISAC 13_118RA2).

Data sharing: Results for all additional analyses and descriptive statistics are already published in the web tables. Any further requests are available from the corresponding author.

The lead author and the manuscript's guarantor (YV) affirms that the manuscript is an honest, accurate, and transparent account of the study being reported; that no important aspects of the study have been omitted; and that any discrepancies from the study as planned and registered have been explained.

This is an Open Access article distributed in accordance with the Creative Commons Attribution Non Commercial (CC BY-NC 4.0) license, which permits others to distribute, remix, adapt, build upon this work non-commercially, and license their derivative works on different terms, provided the original work is properly cited and the use is non-commercial. See: http://creativecommons.org/licenses/ by-nc/4.0/.
1 Department of Economic and Social Affairs. World contraceptive patterns 2013. United Nations, 2013.

2 Lewis M, Heinemann L, MacRae K, Bruppacher R, Spitzer W. The increased risk of venous thromboembolism and the use of third generation progestagens: role of bias in observational research. Contraception 1996:54:5-13.

3 Farmer RDT, Lawrenson RA, Thompson CR, Kennedy JG, Hambleton IR. Population-based study of risk of venous thromboembolism associated with various oral contraceptives. Lancet 1997;349:83-8.

4 Farmer RDT, Lawrenson RA, Todd JC, et al. A comparison of the risks of venous thromboembolic disease in association with different combined oral contraceptives. Br J Clin Pharmacol 2000;49:580-90.

5 Lawrenson R, Farmer R. Venous thromboembolism and combined oral contraceptives: does the type of progestogen make a difference? Contraception 2000;62(2 suppl):S21-8

6 Heinemann LAJ, Lewis MA, Thorogood M, Spitzer WO, GuggenmoosHolzmann I, Bruppacher R. Case-control study of oral contraceptives and risk of thromboembolic stroke: results from International Study on Oral Contraceptives and Health of Young Women. BMJ 1997;315:1502-4.

7 Dinger JC, Heinemann LAJ, Kühl-Habich D. The safety of a drospirenone-containing oral contraceptive: final results from the European Active Surveillance study on Oral Contraceptives based on 142,475 women-years of observation. Contraception 2007;75:344-54

8 Seeger JD, Loughlin J, Eng PM, Clifford CR, Cutone J, Walker AM. Risk o thromboembolism in women taking ethinylestradiol/drospirenone and other oral contraceptives. Obstet Gynecol 2007;110:587-93.

9 van Hylckama Vlieg A, Helmerhorst FM, Vandenbroucke JP, Doggen CIM, Rosendaal FR. The venous thrombotic risk of oral contraceptives, effects of oestrogen dose and progestogen type: results of the MEGA case-control study. BMJ 2009;339:b2921.

10 Seaman HE, de Vries CS, Farmer RDT. Venous thromboembolism associated with cyproterone acetate in combination with ethinyloestradiol (Dianette): observational studies using the UK General Practice Research Database. Pharmacoepidemiol Drug Saf 2004:13:427-36

11 Jick SS, Hernandez RK. Risk of non-fatal venous thromboembolism in women using oral contraceptives containing drospirenone compared with women using oral contraceptives containing levonorgestrel: case-control study using United States claims data. BM 2011;342:d2151

12 Lidegaard $\varnothing$, Nielsen LH, Skovlund CW, Skjeldestad FE, Løkkegaard E. Risk of venous thromboembolism from use of oral contraceptives containing different progestogens and oestrogen doses: Danish cohort study, 2001-9. BMJ 2011;343:d6423.

13 Lewis MA, MacRae KD, Kühl-Habich1 D, Bruppacher R, Heinemann LAJ, Spitzer WO. The differential risk of oral contraceptives: the impact of full exposure history. Hum Reprod 1999;14:1493-9.

14 Parkin L, Sharples K, Hernandez RK, Jick SS. Risk of venous thromboembolism in users of oral contraceptives containing drospirenone or levonorgestrel: nested case-control study based on UK General Practice Research Database. BMJ 2011;342:d2139.

15 Vinogradova Y, Coupland C, Hippisley-Cox J. Exposure to combined oral contraceptives and risk of venous thromboembolism: a protocol for nested case-control studies using the QResearch and the CPRD databases. BMJ Open 2014;4:e004499.

16 Stegeman BH, de Bastos M, Rosendaal FR, et al. Different combined oral contraceptives and the risk of venous thrombosis: systematic review and network meta-analysis. BMJ 2013;347:f5298.

17 Dunn N. The risk of deep venous thrombosis with oral contraceptives containing drospirenone. BMJ 2011;342:d2519.

18 Jick SS, Kaye JA, Vasilakis-Scaramozza C, et al. Validity of the General Practice Research Database. Pharmacotherapy 2003;23:686-9.

19 Hippisley-Cox J, Hammersley V, Pringle M, Coupland C, Crown N, Wright L. Methodology for assessing the usefulness of general practice data for research in one research network. Health Inform ) 2004:10:91-109.

20 Parker C, Coupland C, Hippisley-Cox J. Antipsychotic drugs and risk of venous thromboembolism: nested case-control study. BMJ 2010;341:c4245

21 Vasilakis-Scaramozza C, Jick H. Risk of venous thromboembolism with cyproterone or levonorgestrel contraceptives. Lancet 2001;358:1427-29.

22 Etminan M. Pharmacoepidemiology II: the nested case-control study - a novel approach in pharmacoepidemiologic research. Pharmacotherapy 2004;24:1105-9.

23 Hippisley-Cox J, Coupland C. Predicting risk of emergency admission to hospital using primary care data: derivation and validation of QAdmissions score. BMJ Open 2013;3:e003482.

24 Hippisley-Cox J. Validity and completeness of the NHS Number in primary and secondary care electronic data in England 1991-2013. 2013. www.qresearch.org/PowerPointpresentations/Validity\%20 and $\% 20$ completeness $\% 20$ of $\% 20$ the $\% 20$ NHS $\% 2$ Number $\% 20$ in $\% 20 \% 20$ primary\%20and\%20secondary\%20care\%20data\%20 in\%20England\%201991-2013.pdf. 
25 Sultan AA, West J, Tata LJ, Fleming KM, Nelson-Piercy C, Grainge MJ.Risk of first venous thromboembolism in and around pregnancy: a population-based cohort study. Br I Haematol 2012;156:366-73

26 World Health Organization Collaborative Study of Cardiovascular Disease Steroid Hormone Contarception. Venous thromboembolic disease and combined oral contraceptives: results of international multicentre case-control study. Lancet 1995;346:1575-82.

27 National Institute for Health and Care Excellence. Venous thromboembolic diseases: the management of venous thromboembolic diseases and the role of thrombophilia testing. NICE clinical guideline 144. In: NHS Evidence, 2012.

28 Bird ST, Hartzema AG, Brophy JM, Etminan M, Delaney JAC. Risk of venous thromboembolism in women with polycystic ovary syndrome: a population-based matched cohort analysis. Can Med Assoc 2013;185:E115-20.

29 Lindqvist PG, Epstein E, Olsson $\mathrm{H}$. The relationship between lifestyle factors and venous thromboembolism among women: a report from the MISS study. Br J Haematol 2009;144:234-40.

30 French R, Mercer C, Johnson A, Fenton K, Erens B, Wellings K. Use of contraceptive services in Britain: findings from the second National Survey of Sexual Attitudes and Lifestyles (Natsal-2). J Fam Plann Reprod Health Care 2009;35:9-14.

31 White RH, Zhou H, Romano PS. Incidence of idiopathic deep venous thrombosis and secondary thromboembolism among ethnic groups in California. Ann Intern Med 1998;128:737-40.

32 Hippisley-CoxJ, Coupland C. Development and validation of risk prediction algorithm (QThrombosis) to estimate future risk of venous thromboembolism: prospective cohort study. BMJ 2011;343:d4656.

33 Royston P. Multiple imputation of missing values. Stata J 2004; 4:227-41.

34 Borenstein M, Hedges L, Higgins J, Rothstein H. A basic introduction to fixed-effect and random-effects models for meta-analysis. Res Syn Meth 2010;1:97-111.

35 Bjerre L, LeLorier J. Expressing the magnitude of adverse effects in case control studies: "the number needed to be treated for one additional patient to be harmed”. BMJ 2000;320:503-6.

36 Lader D. Opinions survey report no 41. Contraception and Sexual Health, 2008/09. Office for National Statistics: NHS The Information Centre for health and social care, 2009. www.ons.gov. uk/ons/rel/lifestyles/contraception-and-sexualhealth/2008-09/2008-09.pdf.

37 Vaughan B, Trussell J, Kost K, Singh S, Jones R. Discontinuation and resumption of contraceptive use: results from the 2002 National Survey of Family Growth. Contraception 2008;78:271-83.

38 The Health and Social Care Information Centre. NHS Contraceptive Services: England, 2004/05. 2005. www.hscic.gov.uk/catalogue/ PUB00097/nhs-cont-serv-eng-2004-2005-rep.pdf.
39 Heinemann LAJ, Dinger JC. Range of published estimates of venous thromboembolism incidence in young women. Contraception 2007;75:328-36.

40 Lawrenson R, Todd JC, Leydon GM, Williams TJ, Farmer RD. Validation of the diagnosis of venous thromboembolism in general practice database studies. Br J Clin Pharmacol 2000;49:591-6.

41 Rothman KJ, Pool C. A strengthening programme for weak associations. Int J Epidemiol 1988;17:955-9.

42 Heinemann K, Heinemann LAJ. Comparative risks of venous thromboembolism among users of oral contraceptives containing drospirenone and levonorgestrel. J Fam Plann Reprod Health Care 2011;37:132-5

43 Briggs PE, Praet CA, Humphreys SC, Zhao C. Impact of UK Medical Eligibility Criteria implementation on prescribing of combined hormonal contraceptives. J Fam Plann Reprod Health Care 2013;39:190-6.

44 Jick SS, Kaye JA, Russmann S, Jick H. Risk of nonfatal venous thromboembolism with oral contraceptives containing norgestimate or desogestrel compared with oral contraceptives containing levonorgestrel. Contraception 2006:73:566-70.

45 Heinemann LAJ, Dinger JC, Assmann A, Minh TD. Use of oral contraceptives containing gestodene and risk of venous thromboembolism: outlook 10 years after the third-generation "pill scare". Contraception 2010;81:401-7.

46 Heinemann LAJ, Lewis MA, Assmann A, Thiel C. Case-control studies on venous thromboembolism: bias due to design? A methodological study on venous thromboembolism and steroid hormone use. Contraception 2002;65:207-14.

47 Eastwood BJ, Gregor RD, MaClean DR, Wolf HK. Effects of recruitment strategy on response rates and risk factor profile in two cardiovascular surveys. Int I Epidemiol 1996;25:763-9.

48 Gronich N, Lavi I, Rennert G. Higher risk of venous thrombosis associated with drospirenone-containing oral contraceptives: a population-based cohort study. CMA/ 2011;183:E1319-25.

49 Kuhnz W, Blode H, Mahler M. Systemic availability of levonorgestre after single oral administration of a norgestimate-containing combination oral contraceptive to 12 young women. Contraception 1994:49:255-63.

50 Lidegaard $\varnothing$, Milsom IAN, Geirsson RT, Skjeldestad FE. Hormonal contraception and venous thromboembolism. Acta Obstet Gynecol Scand 2012:91:769-78.

(C) BMJ Publishing Group Ltd 2015

Web appendix 1: Supplementary tables Web appendix 2: READ codes of conditions affecting venous thromboembolism 